\title{
EXPLORING KEY ELEMENTS REQUIRED FOR ORgaNizATIONAL TRUST AND THE CONSEQUENTIAL IMPACT ON KNOWLEDGE SHARING WITHIN ORGANIZATIONS
}

\author{
Robin Zarine and Muhammad Saqib \\ Department of Computing, Middle East College, KOM, Muscat, Sultanate of Oman
}

\begin{abstract}
This paper focuseson the status of organizational trust in Muscatand its impact on organizational learning $(O L)$ which is based on the willingness of employees sharing knowledge gathered through experience to improve organizational performance and sustainable competitiveness [1]. Online structured questionnaire andMicrosoft Excel used to collect and analyze the data showed significant organizational trust exist within organizations including organizational transparency, management style, employees' welfare and support, and job security. But still, minimalOL and sharing was happening contradicting theories that suggest organizational trust leads to important group collaboration, willingness of employees to share knowledge gathered through their experience and its close link to OL. Lack of compassion and being too controlling at timeswere also raisedas concerns and existing knowledge sharing technological support were also not having much impact. Bringing people together for more effective communications among teams and promoting knowledge sharing culture can lead the way.
\end{abstract}

\section{KEYWORDS}

Organizational trust, Trust Management, Learning and knowledge sharing

\section{INTRODUCTION}

Organizational trust may be viewed as developing trust among colleagues thus leading to important group collaboration [2] and employees' willingness to be exposed to organization's actions where such willingness is based on clear communication of organization's action in between employees and organizations, be it through informal or formal means [3]. It also relates to employee job satisfaction and overall perception of organization's effectiveness through measurement like competence, openness and honesty, reliability and identification.

Trust has been recognized as a needed factor for any relationship building, be it social, economic or political such as employee and /or customer loyalty towards organizations, organizational alliance, cross-cultural communication, bilateral or multilateral agreements and even learning [4]. Trust is not always easily achieved so that is why it is gaining more and more attention in public discussions and academic studies. Paliszkiewicz also suggested that trust can be solid foundations for crucial dealings in life whether it is friendship development, dialogues aiding and political issues resolving, be it local, regional or international, cross-cultural agreements enabling, and even investment choices influencing. Saunders et al. also view trust to be very influential in safeguarding workable relations among dissimilar parties; in particular parties with different cultural background [5]. It will consequently, positively impact performance be it an individual, a 
group or an organization level. Therefore it is crucial to appreciate the importance of trust and its management especially in organizations.

This paper is based on an empirical research focusing on the existing trust within private and public organizations in Oman and its impact on knowledge sharing within those organizations. Such type of trust is referred to as organizational trust and is generally defined as positive expectations of individuals with regards to intents and behaviours of organizational members in relation to organizational roles, relationships, experiences and interdependencies [6]. The paper will also highlight some of the factors that need to be in place to promote organizational trust and the consequential impact on the knowledge sharing culture.

\section{LITERATURE REVIEW}

\subsection{Trust Definition}

Trust is simply one's expectations that the behaviour of other parties with whom he/she interact or corporate with, be it individuals, groups or organizations, will be favourable to his/her wellbeing [7]. Since normally one party would be independent of the other, it means that each party is taking some sort of a gamble when choosing to trust each other which is in line with Blomqvist interpretation that suggest trust can be viewed as one person's preparedness to be exposed to another person's uncertain forthcoming behaviours based on past actions [8]. This willingness to be exposed is based on three dimensions identified by Nyhan and Marlowe and these are appropriate invested effort to act in accordance to pledges made among the participating parties, truthfulness demonstrations during discussions, and refrain from taking disproportionate advantage of each other [9].

Khodyakov relates trust to having the interacted parties being rational when it comes to decisionmaking which link with ideas of honesty and morality [10]. In turn, such behaviors will influence how one will choose to trust, as past behaviors will influence the trust level a party will be willing to give at present and in the future. Barbalet argues that trust cannot be based on rational calculations as rational calculations relate to present situations rather than future situations which are closer linked to the characteristics of trust [11]. He further explains that a party will choose to trust another party based on outcomes that are yet to occur as trust decision time always precede the related outcomes which the trust will be based on. Therefore, trust may be fairly risky as the expectations of one party always talk about to the yet to come actions of the other party. Creed and Miles view trust as some combination of characteristic similarity and positive relational experience, with broad societal norms and expectations [12]. They perceive those as the original expectations of common trustworthiness and therefore, the stronger their existence, the higher will the level of trust would be.

Some of the common features of the concepts of trust are identified by Paliszkiewicz as interpersonal through good communication, situational rather than global, voluntary rather compulsory, commitment based, mindful of each other's trust, action-oriented and dynamic as it keeps evolving [4]. It is to be noted that trust is an imperative instrument in our life, as it helps us to get by the uncertainty that may arise due to the uncontrollable actions of other independent parties [13].

\subsection{Trust Management}

As mentioned before, trust is dynamic as it keeps evolving and it may evolve positively or negatively based on the continuous behaviours of the participating parties. Considering the many 
benefits that can be reaped by having trusted partners transacting, it is crucial to manage the achieved trust level or even increase the trust level wherever possible. Trust management may be viewed as a cycle where initially trust relationships are developed, set up monitoring approaches of each party's behaviour while inter party's transactions take place, and then determine the level of trust each party would be willing to allow for the other participating party [13]. Trust management based on this cycle can provide each participating party with the necessary knowledge of other participating parties and so that more informed authorization decisions may be taken.

Trust management has many advantages to offer participating parties as described by Ardagna et al. Trust management ensures appropriate authentication and authorization of participating parties during transactions, allows each participating party to define and regulate their own transacting policies, supports designation and allows reorganization of control among participating parties, and review of restrictions and conditions without much hindrance [14].

\subsection{Organizational Trust}

Organizations are groups of people brought together to work towards achieving a specific set of goals [15]. To achieve such set of goals, the people brought together need to pull their efforts towards the same direction meaning they have to cooperate with each other and that cooperation requires trust among the co-workers and in the leading team. This kind of trust may be referred to as organizational trust and how it develops somehow relate to the practice of the leading team as suggested by research relating transformational leadership with employees' trust in their leaders [16]. The authors also stressed on the significance of the trust building processes in between the employees and the leading team which is supported by Dursun who highlighted that organizational trust will even be stronger while employees sense a supportive organizational environment [15]. Therefore, the consequences of any violations of the employees' trust by the leading team will result in jeopardizing organizational trust and subsequently the initial purpose of setting up organizations.

At present, there is no specific definition for organizational trust but many authors have made good attempts to try and capture its principles. Some attempts include organization's willingness to take a gamble on its transacting partner to behave as per its expectations where such willingness is mainly based upon its culture and communication behaviours in relationships and transactions [17] while Lee and Stajkovic relate organizational trust as developing trust among colleagues thus leading to important group collaboration which in turn may result in accrued social capital [2]. Tan and Lim view organizational trust as employees' willingness to be exposed to organization's actions where such willingness is based on clear communication of organization's action in between employees and organizations, be it through informal or formal means [3]. Employees' immediate social environment which mainly consists of colleagues can be a vital medium for such communication. It can also be interpreted as the belief of employees that the work being done by their organizations would result in benefits rather than harm to them though they do not have any say in the decision making process thus the willingness to be vulnerable.

Other attempts to define organizational trust include the positive expectations of individuals with regards to intents and behaviours of organizational members in relation to organizational roles, relationships, experiences and interdependencies [6]. They relate organizational trust to employee job satisfaction and overall perception of organization's effectiveness which are measured using competence, openness and honesty, reliability and identification. Ralston followed a similar line of argument relating organizational trust to either rational or relational occurrence that is based on interpersonal connections or cooperative associations amongst the trusting parties [18]. 
Positive changes within the organizational working environment, be it, social or economic, demonstration of gratefulness to team effort, noticeable and appropriate level of effort made to deliver on promises and refraining from taking unwarranted advantage of employees by the organizations are key elements described by Nyhan and Marlowe for strengthening organizational trust [9] and therefore making organizational trust measurable by emotional, cognitive and intended behaviour.

\subsection{Organizational Learning}

The importance of organizational trust is quite noticeable especially for organizational learning and organizational performance [19]. King describes organizational learning as the continuous incorporation of what has been learnt into the processes of the organization [20] which is fairly similar to the description given by Drucker referring to the willingness of employees to share knowledge gathered through their experience to be used as enrichment parts to existing processes thus improving organizational performance and becoming competitively sustainable [1]. Such willingness relate significantly to the concept of interpersonal or organizational trust but unfortunately, the concept of organizational trust in not necessarily getting its well merited attention even when perceived trustworthiness of an organization is on the decline [21] and so is the organizational learning. Rather organizational leaders frequently view trust defensively and possibly hinder the so well valued concept of organizational learning. After all, organizational learning depends on people learning which is basically acquiring new knowledge and managing them effectively.

\section{Building Organizational Trust}

It has been argued that organizational trust is crucial for organizational learning which leads to better organizational performance [19] and organizational distrust will negatively impact organizational performance as employees tend to become less efficient [4]. Paliszkiewicz argues that the dividends of high trust can also be calculated to justify the need for building trust and even make it an explicit objective. Just like any objective, it must be measured and monitored so that appropriate remedial actions may be taken to ensure continuous improvement. The leading team needs to make it a high priority to ensure that distrust situations are identified and eliminated; creates regularly opportunities to allow for demonstration of positive relational signals; and institutionalized trust by integrating them within the organizational policies.

Creed and Miles argue that by increasing perceived similarities and the number of optimistic talks among participated parties, the trust level will increase [12].

\section{KNOWLEDGE SHARING}

The process of Knowledge Management (KM) is essentially about making the better decisions using knowledge and the available knowledge sources. The most important roles including people, technology and processes are playing in this regard within the organizations. The life cycle of KM thus shows a smooth flow of knowledge through capturing to creation further knowledge. Perhaps one of the most important single aspect in this process is knowledge sharing. It is an activity to exchange knowledge namely information, skills and or expertise among individuals, groups and or communities. Vast majority of KM initiatives are depending on it. In its simple terms can be called as either pull or push mechanism.

It is quite true that sharing totally depends on the willingness and or the habit of individuals. In order to understand the potential issues or complexities of sharing, managing knowledge and or 
user requirements, organizations must first create a trustworthy knowledge culture. Already such processes, framework and systems are available to adapt and implement within organizations. A trustworthy and knowledge sharing culture are itself the fuel of organization performance. Collaborative innovation and trust is becoming increasingly important as it promotes the knowledge sharing culture which normally leads to good practices thus resulting in overall performance enhancement [22]. Organizations acquire any knowledge; the knowledge must be shared within units/departments whenever they need to further develop the knowledge-based systems or in dealing with any challenges. According to Newman and W. Conrad, the knowledge sharing is an important component of organizational success and the quicker the knowledge diffusion takes place, the greater the response time to problem solving would be and therefore the better the organizational performance would be [23], [24].

\section{Methodology}

According to Industrial Research Institute, methodology is defined as a way of searching or solving the research problem. It is a broad strategy to be undertaken to outline the objective. It's an organized and notional analysis of methods and principles applied in order to explore; encompasses the concepts of theoretical model, paradigm, phases and techniques of quantitative and qualitative research [25]. The current study intends quantitative research method. It directs suitable simple technique of data collection and analysis tool using online structured questionnaire, while explaining trust within organizations; it further examines the relationship between trust and knowledge sharing. Hence, it is characterized as descriptive and correlational study.

Additionally, the present study has deployed a survey method using online Google Doc. Survey methods are significant and applicable. It helps in various types of data collection, variable computation and analyses hypotheses [26]. Other benefits of survey methods are the accessibility to a good number of respondents, on-site enquiry and bias-less manageability [27, 28]. Thus, it was fruitful to use survey method with structured questionnaire to carry out this research study (adapted and modified from Corbitt, Thanasankit and Yi (2003), Annick Willem Marc Buelens (2007) and [23]). Furthermore, question-wise data analysis is done using MS Excel 2013 and as literature reveals and depending on the context and nature of research study, unit of investigation was public and private sector employees of organizations within Muscat, Sultanate of Oman. The targeted employees were also all studying knowledge management either at Bachelor's level or Master's level implying good understanding of the topics covered by the questionnaire.

Based on the different research results presented earlier, some key elements relating to organizational trust and organizational learning (knowledge sharing) were identified and used as the base for the questions needed for the research. So the measuring instrument is based on overall perception of organization's effectiveness such as openness, honesty, reliability, support and knowledge sharing.

\section{RESUlt ANALYSIS}

In the result analysis, the key elements that employees consider to be important for generating organizational trust are identified and also the elements that they consider to be hindrance to the development of organizational trust are looked at. An attempt to interpret the segment of employees having a neutral view is also presented.

Based on the data collected, majority of employees (79\%) feel that their current organization has proven to be trustworthy and therefore they would feel comfortable enough to recommend a 
friend to join them. Justifications for the trust included the ways their organizations handle important decisions relating to them, whether or not it is a new situation. There is the feeling that employees' welfare are always being considered, positive reaction from their organizations are received even when their weaknesses are exposed, and increasingly transparent practices are being adopted by their organizations with regards to keeping them informed of the happenings within their organizations.

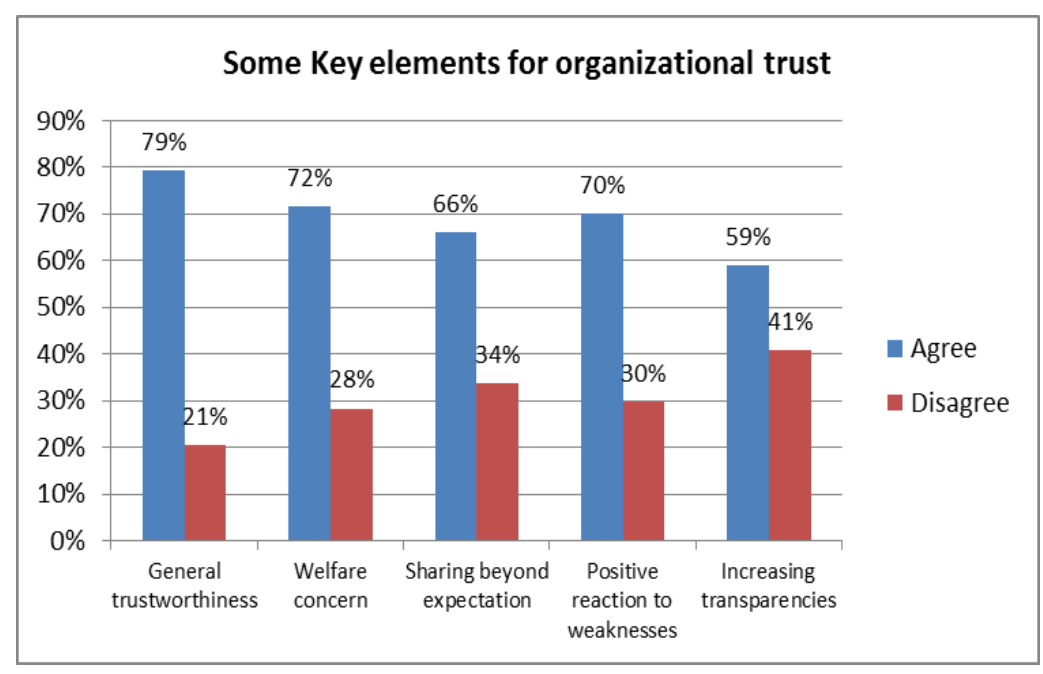

Figure 1. Key Elements of Org Trust

Furthermore, the employees feel that their organizations are doing very well in keeping their promises and would not be dishonest even if the opportunity should arise without the employees' awareness. They also feel their jobs are well secured and the necessary supports are provided even when venturing into unknown areas due to requirement for completing assigned tasks. Significant collaborations in between employees and management exist which consequently develops an approachable management style encouraging exchange of views whether for positive contributions or concerns. These factors seemingly develop the employees' trust towards their organizations. The results are fairly in line with the dimensions identified by Nyhan and Marlowe which include appropriate invested effort to act in accordance to pledges made among the participating parties, truthfulness demonstrations during discussions, and refrain from taking disproportionate advantage of each other (Nyhan and Marlowe 1997) showing existence of organizational trust

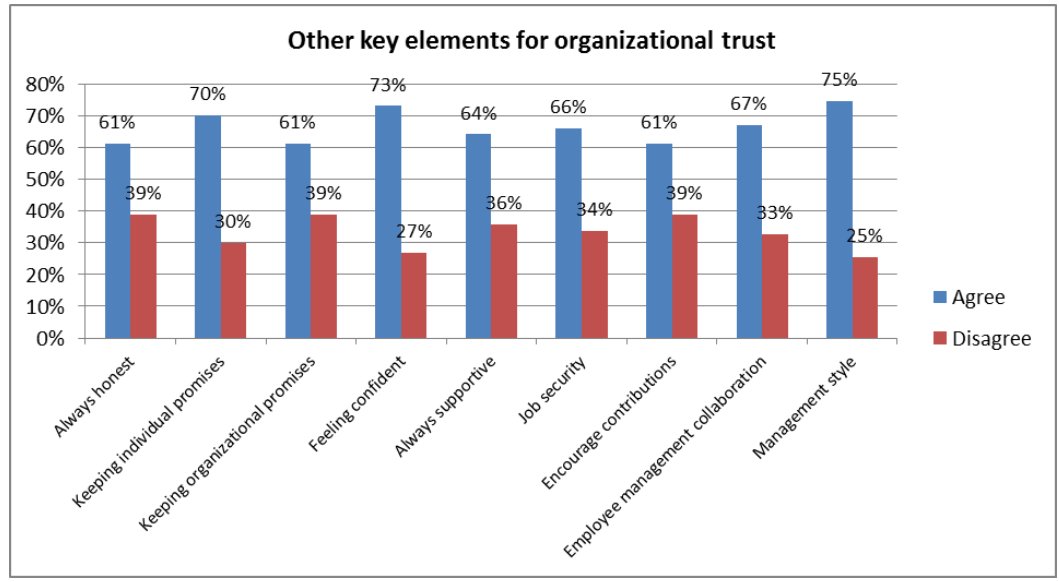

Figure 2. Other key Elements 
On the other hand though, there is a fairly evenly divided view on a few points with some instances inclining negatively. These points may be viewed as points that employees view as concerns that seemed to hinder the development of individual trust thus the organizational trust within the organizations. These include the lack of compassions towards personal problems, bringing up past events during disagreements or arguments, and organizations occasionally try to be controlling overlooking the importance of mutual respect. This appears to instill in some employees an unforgiving nature towards their organizations if it happens that their organizations significantly deviate from their expectations. It can also frustrate them to the extent of leaving their current organizations without much thought if better offer should arise which is not normally beneficial to any organization particularly if the leavers are the organization's knowledge workers.

As pointed out before, trust is dynamic as it keeps evolving and it may evolve positively or negatively based on the continuous behaviors of the participating parties. Therefore the organizations in Oman may need to emphasize more on managing organizational trust to mitigate those elements that may result in organizational distrust thus losing out on the many benefits that can be reaped from it.

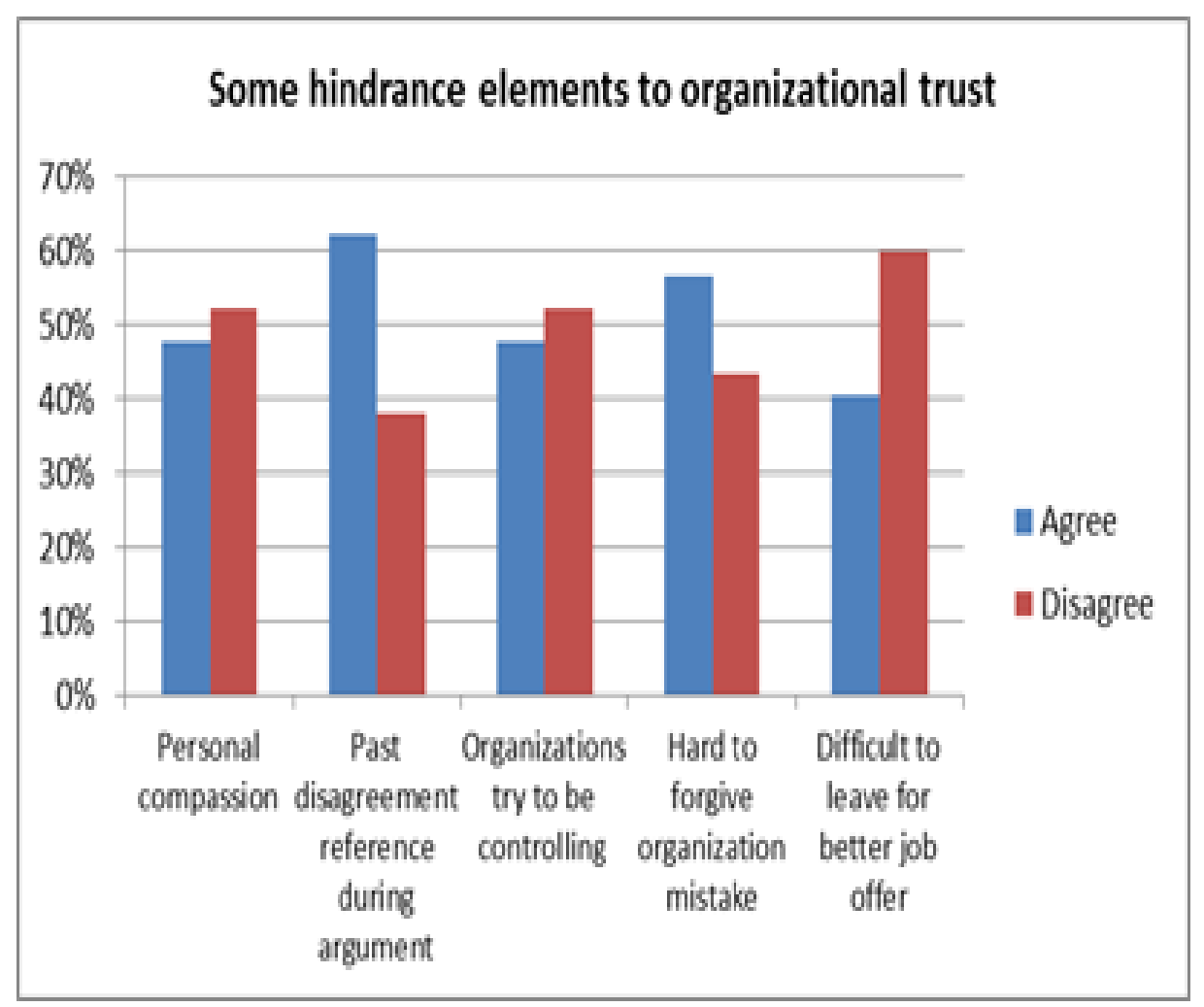

Figure 3. Hindrance Elements

Despite the inclination of employees' trust towards their organizations, that trust does not seem to be translating into a knowledge sharing catalyst for the organizations as knowledge sharing in between and within departments is still fairly limited. Though organizations tend to emphasize on collaborative technologies (58\%) (such as internet \& intranet) to allow for knowledge sharing, not much appears to be happening in terms of bringing people together (inter-departmental meeting, etc.). 


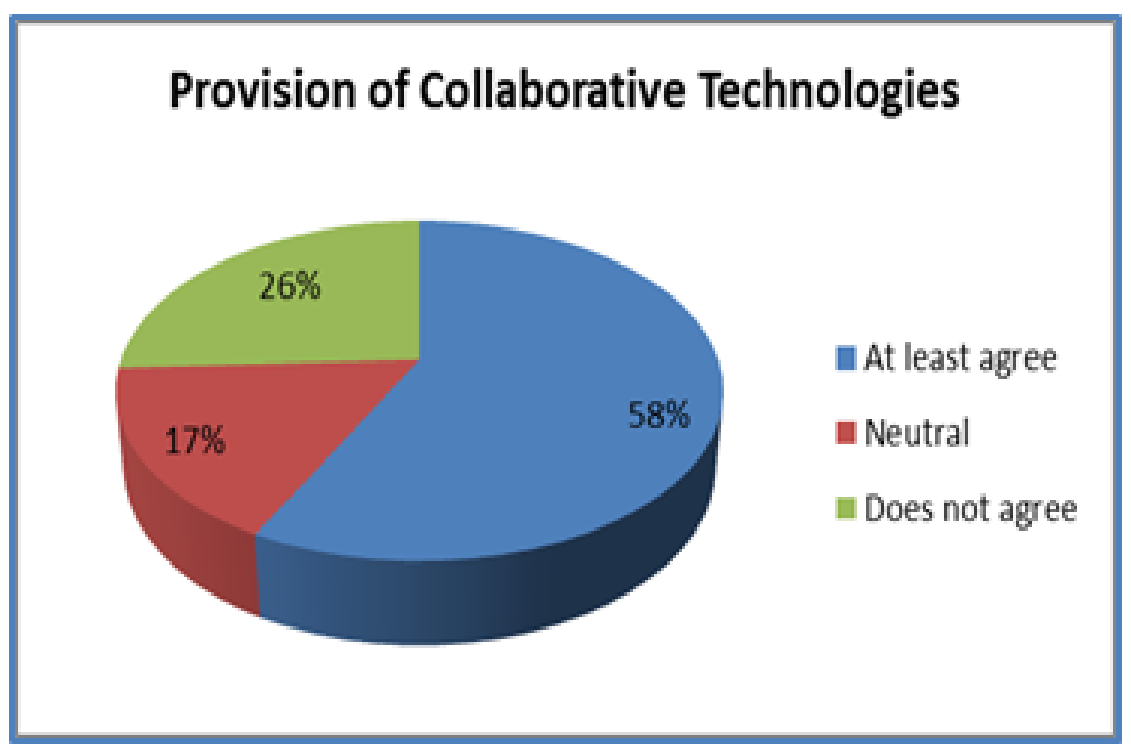

Figure 4. Collaborative Technologies

Only by bringing people together (acquaintances) can guarantee more effective communication among departmental management team to discuss new ideas, programs and activities that are useful to the organizations. The encouragement for developing a reliable knowledge sharing culture also tends to be fairly blurred and incentive systems that usually provide recognitions for employees' knowledge contributions are not being used much.

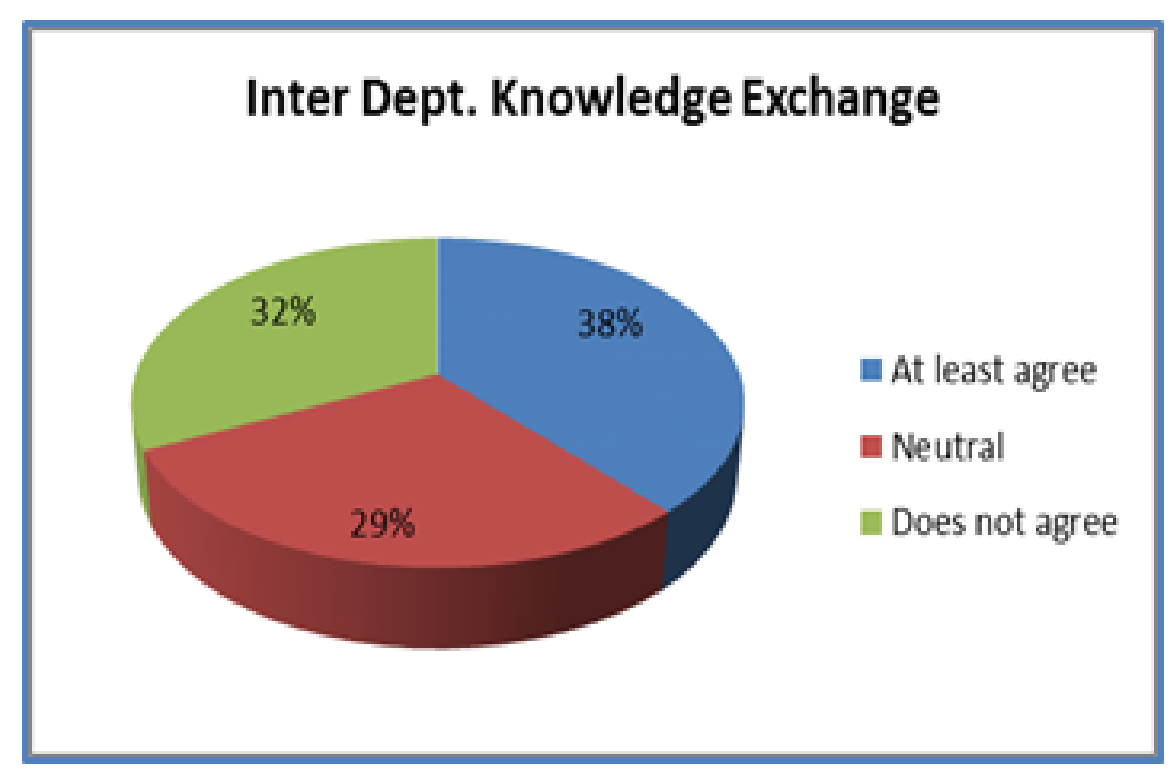

Figure 5. Knowledge Exchange

The figures below show the other related results and it can be noted that all the responses that relate to positive contribution towards knowledge sharing fall below $50 \%$. 
International Journal of Managing Information Technology (IJMIT) Vol.10, No.4, November 2018

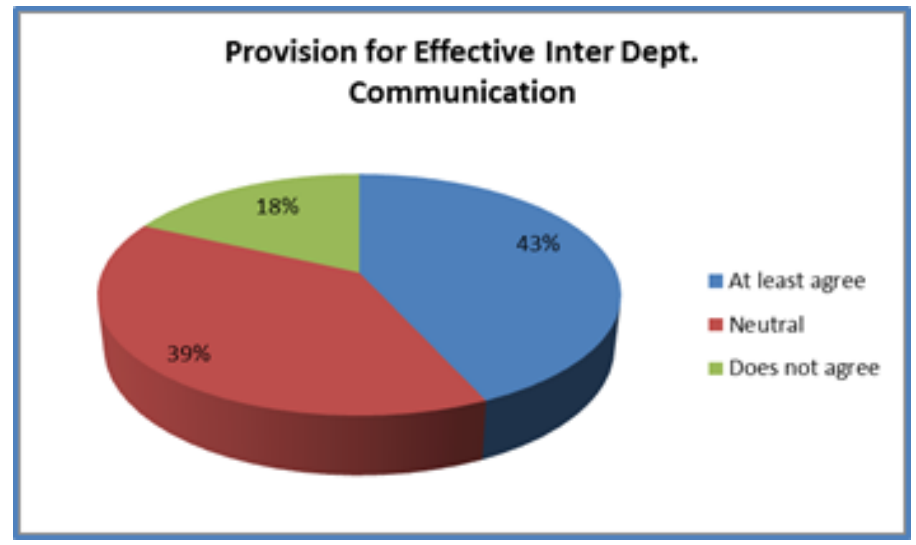

Figure 6. Inter Dept. Communication

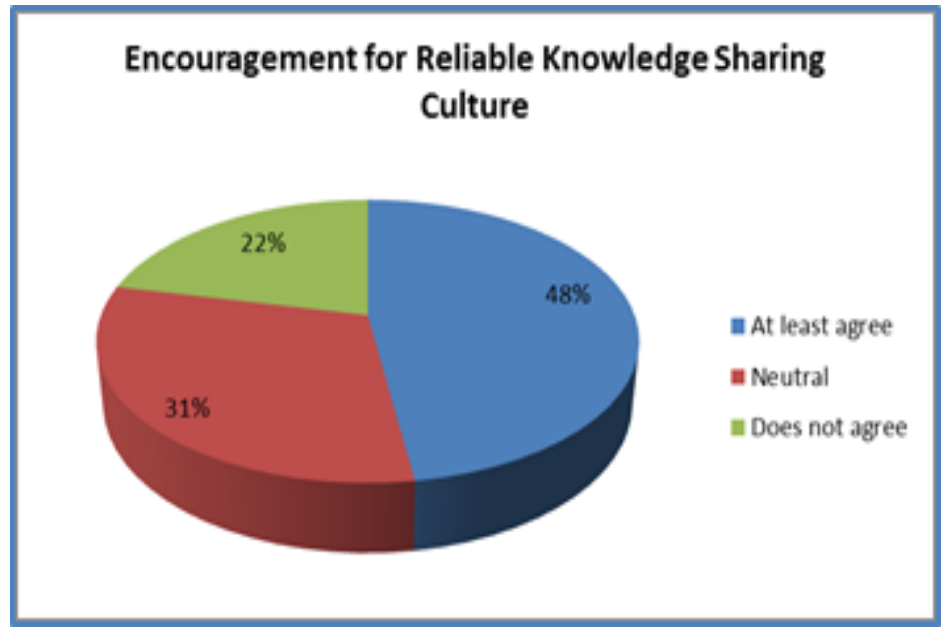

Figure 7. Knowledge Sharing Culture

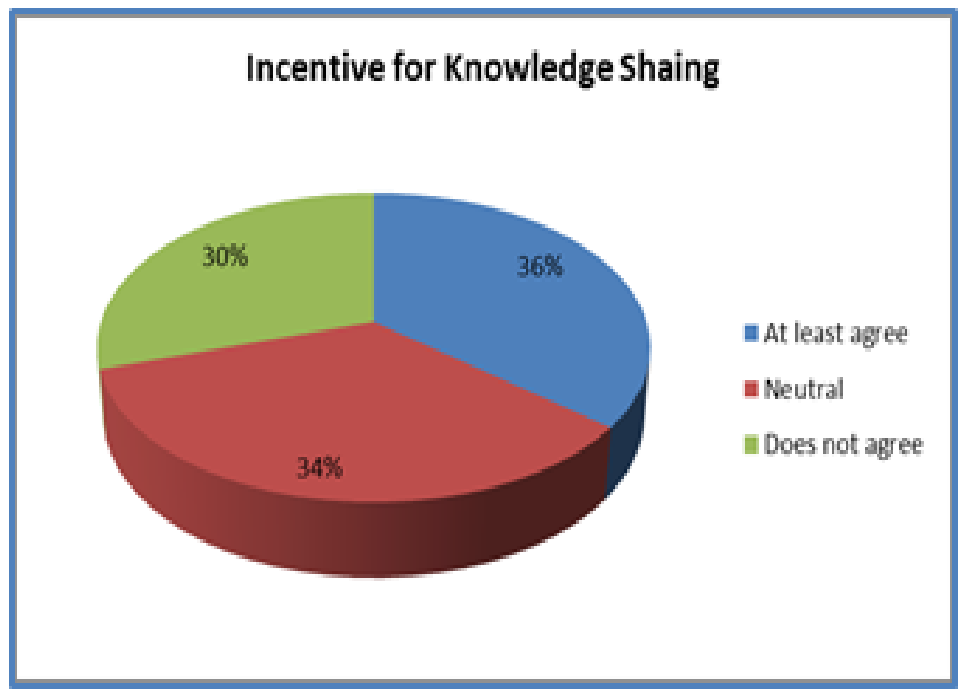

Figure 8. Incentive 
From the results, it can also be noted that a significant number of employees had a neutral view of knowledge sharing practices within their organizations (ranging from 29\% to 39\%). Given their familiarity (targeted group) with the knowledge sharing concepts, it should be quite interesting to further investigate and establish clearly the reasons for them to be taking such position. It can be fairly safe to assume that employees are not even paying much attention to the concept of organizational learning (knowledge sharing) and therefore some sort of education and awareness campaign be put in place.

\section{CONCLUSIONS}

It is clear that significant organizational trust exist within both the public and private organizations in Muscat, Oman. The existence of the organizational trust is a result of practices such as organizational transparency, management style, employees' welfare and support, and job security. On the other hand, lack of compassion and being too controlling at times are identified as concerns that need addressing to mitigate organizational distrust. Furthermore, the existence of organizational trust is not assisting with the organizational learning (knowledge sharing) as expected which should also be looked at closer.

Also it can be deduced that without bringing people together to ensure more effective communications among departmental teams and promoting of knowledge sharing culture, related collaborative technologies alone will not have much impact too.

Furthermore, some sort of education and awareness campaign need to be introduced within the organizations to promote the concept of organizational learning (knowledge sharing) which hopefully can develop the necessary appreciation by the employees.

\section{REFERENCES}

[1] P. Drucker, "Knowledge-worker productivity: The biggest challenge," California Management Review, 1999.

[2] D. Lee and A. D. Stajkovic, "Interpersonal trust and emotion as predictors of cooperation in work teams," 2005.

[3] H. Tan and A. Lim, "Trust in Coworkers and Trust in Organizations," The Journal of Psychology, 2009.

[4] J. O. Paliszkiewicz, "Trust Management: Literature Review," Management, vol. 6, no. 4, pp. 315$331,2011$.

[5] M. Saunders, D. Skinner, G. Dietz, N. Gillespie, and R. Lewicki, Organizational Trust: A Cultural Perspective. New York: Cambridge University Press, 2010.

[6] P. Shockley-Zalabak, K. Ellis, and G. Winograd, "Organizational trust: What it means, why it matters," Organization Development Journal, vol. 18, no. 4, pp. 35-48, 2000.

[7] P. Szompta, Trust: A socialogical theory. Cambidge: Cambridge University Press, 1999.

[8] K. Blomqvist, "TRUST IN KNOWLEDGE-BASED ORGANIZATIONS," School of Business, Lappeenranta University of Technology. 
International Journal of Managing Information Technology (IJMIT) Vol.10, No.4, November 2018

[9] R. Nyhan and H. Marlowe, "Development and psychometric properties of the organizational trust inventory," 1997.

[10] D. Khodyakov, "Trust as a process: A three-dimensional approach," Sociology, vol. 41, pp. 115132, 2007.

[11] J. Barbalet, "A characterization of trust and its consequences," Economic and research council, 2006.

[12] D. Creed and R. Miles, Trust in Organizations: A Conceptual Framework Linking Organizational Forms, Managerial Philosophies, and the Opportunity Costs of Controls. 1996.

[13] S. Ruohamaa and L. Kutvonen, "Trust management survey," 2007.

[14] C. Ardagna, E. Damiani, S. De Capitani di Vimercati, S. Foresti, and P. Samarati, "Trust Management," Springer Berlin Heidelberg, 2007.

[15] E. Dursun, "The relationship between organizational trust, organizational support and organizational commitment," African journal of Business Management, vol. 9, no. 4, Feb. 2015.

[16] D. Den Hartog, M. Shippers, and P. Koopman, "THE IMPACT OF LEADER BEHAVIOUR ON TRUST IN MANAGEMENT AND CO-WORKERS," Journal of Industrial Psychology, 2002.

[17] T. Gills, "More than a Social Virtue: Public Trust among Organizations' Most Valuable Assets," Communication World, 2003.

[18] E. Ralston, "Structure of organizational trust in military-type and civilian organizations: Validation of the Organizational Trust Questionnaire," Retrospective Theses and Dissertations, 2006.

[19] R. Shaw, "Trust in the balance," San Francisco: Jossey-Bass, 1997.

[20] W. King, "Knowledge management and organizational learning," Annals of Information Systems, 2009.

[21] T. Tyler and R. \& Kramer, "Whither trust?," Thousand Oaks, CA:Sage, 1996.

[22] H. F. Lin, "Knowledge sharing and firm innovation capability: an empirical study," International Journal of manpower, vol. 28, no. 3/4, pp. :315-332, 2007.

[23] M. Saqib, Z. M. Udin, and N. Baluch, "The Impact of Knowledge Management on Organizational Performance in Today's Economy," South East Asian Journal of Contemporary Business, Economics and Law, vol. 12, no. 3, pp. 25-33, Apr. 2017.

[24] B. D. Newman and K. W. Conrad, "A Framework for Characterizing Knowledge Management Methods, Practices, and Technologies," in International Conference on Practical Aspects of Knowledge Management, Basel, Switzerland, 2000, pp. 16-1-16-11. [Online].<a href="http://sunsite.informatik.rwth-aachen.de/Publications/CEUR-WS/Vol-34/

">http://sunsite.informatik.rwth-aachen.de/Publications/CEUR-WS/Vol-34/ </a>

[25] U. Sekaran and R. Bougie, Research Methods for Business: A Skill Building Approach. New York: John Wiley \& Sons Inc., 2010. 
International Journal of Managing Information Technology (IJMIT) Vol.10, No.4, November 2018

[26] W. 1. Neuman, Social Research Methods: Qualitative and Quantitative Approaches, 3rd ed. Allyn and Bacon, 1997.

[27] A. Bryman and E. Bell, Business Research Methods. New York: Oxford University Press Inc., 2003.

[28] U. Sekaran and R. Bougie, Research Methods for Business: A Skill Building Approach . New York: John Wiley \& Sons Inc., 2010.

[29] G. Dietz and N. Gillespie, "Building and restoring organizational trust," The Institute of Business Ethics.

[30] W. E. D. Creed and R. E.Miles, "Trust in Organizations:A Conceptual Framework Linking Organizational Forms, Managerial Philosophies and the Opportunity Costs of Controls," Trust in organizations: Frontiers of theory and research, 1996.

\section{Authors}

Robin Zarine is a Senior Lecturer in Computer Science and ICT Management at the Middle East College in Oman. He is actively involved in the planning and the quality management of the institution. His research interest includes technological impact on pedagogy, adoption of technology within HEIs, organisational trust and knowledge management and sharing within organisations. He has published conference and journal papers.

Dr. Muhammad Saqib is Associated with MEC as Senior Lecturer and Program Manager for the last five years and involve with teaching and research for the last 12 years. His areas of interest are knowledge management and business intelligence, technology management and sustainable innovations. He has published a number of journal and conference papers.
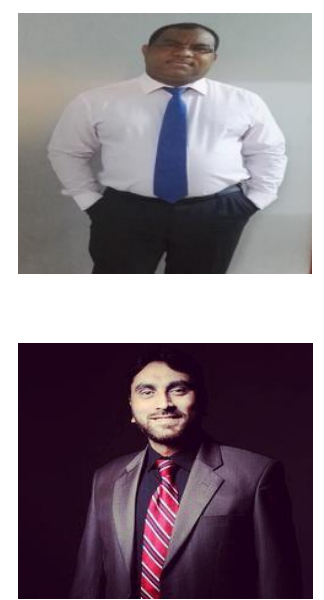